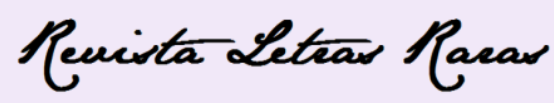

ISSN: 2317-2347 - Vol. 5, Ano 5, № 1 - 2016

\title{
Travessias subjetivas e históricas: o sujeito na linguagem
}

\author{
Hermano de França Rodrigues*
}

Resumo: A Linguística Moderna desponta, originalmente, no panorama das Ciências Humanas, extasiada pelos princípios da autonomia e da regularidade. Pelo menos, é a impressão que temos ao sermos introduzidos, sob os efeitos da ingenuidade, em sua gênese e gestação. O seu criador, Ferdinand de Saussure, engendrou uma ciência cujo objeto parece, aos olhos descuidados, ter livre existência e equilíbrio constante. É a língua, no Curso de Linguística Geral (SAUSSURE, 1989), a responsável por estabelecer e manter as relações elementares dentro do sistema. As famosas associações sintagmáticas e paradigmáticas insurgem imunes à intervenção de um sujeito, como se configurassem "casualidades" contínuas, acarretadas pelo próprio fenômeno linguístico. Do mesmo modo, o liame arbitrário entre o significante e o significado, fator que assegura as contingências semânticas do signo é, frequentemente, vislumbrado como um processo de autorregulagem sistêmica, regido pelas leis intrínsecas ao evento. A maneira como tais reflexões insurgem pela escrita do CLG, não de "autoria" do mestre genebrino, mas de seus discípulos-editores, induzem muitos estudiosos a interpretações limitadas, amiúde, equivocadas. Resulta, daí, a crença na rígida separação entre língua e fala, sincronia e diacronia, que perpetraram as "indestrutíveis" e polêmicas dicotomias saussureanas. Nossa pesquisa, de natureza bibliográfica, consiste em discutir a presença e o apagamento, sub-reptícios, da categoria de sujeito nas teorizações que compõem o CLG. Para tanto, recorreremos aos trabalhos de BARBOSA (1996), BARTHES (1984), FIORIN (2002), CÂMARA JR (1975), dentre outros.

Palavras-chave: CLG. Sistema. Sujeito.

\section{CROSSINGS SUBJECTIVE AND HISTORICAL: THE SUBJECT IN LANGUAGE}

\begin{abstract}
The Linguistics Modern emerges originally in the panorama of the humanities, enraptured by the principles of autonomy and regularity. At least, is the impression that we have to be introduced, under the effects of ingenuity in its genesis and gestation. Its creator, Ferdinand de Saussure, begot a science whose object appears to careless eyes have free existence and constant balance. It is the language, in Course in General Linguistics Geral (SAUSSURE, 1995), responsible for establishing and maintaining the basic relationships within the system. The famous syntagmatic and paradigmatic associations rebel immune to the intervention of a subject, as they would configure "casualties" continuous, brought about by the own linguistic phenomenon. Similarly, the arbitrary link between the signifier and the signified, a factor that ensures the semantic contingencies sign is often envisioned as a systemic auto-tuning process, governed by laws intrinsic to the event. The way these reflections rebel by writing CLG, not "authored" the genevan master, but his disciples editors induce many scholars to limited interpretations, often, misleading. It follows, then, belief in rigid separation between language and speech, synchrony and diachrony, who perpetrated the "Indestructible" and polemical dichotomies saussurean. Our research, bibliographic order, is to discuss the presence and deletion, surreptitious, the category of subject in theorizing that make up the CLG. Therefore, we will use the work of BARBOSA (1996), BARTHES (1984), FIORIN (2002), CÂMARA JR (1975), among others.
\end{abstract}

Keywords: CLG - System - Subject

\section{Preliminares} ${ }^{*}$ Doutor em Letras, pela Universidade Federal da Paraíba. Professor Adjunto III, do Departamento de Letras
Clássicas e Vernáculas, da UFPB. E-mail: hermanorg@gmail.com. 


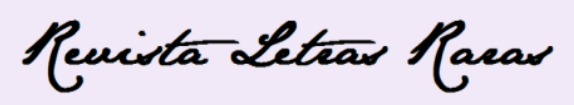

ISSN: 2317-2347 - Vol. 5, Ano 5, № 1 - 2016

Certamente, estaríamos cometendo um erro de proporções indefinidas se afirmássemos que o Pai da Linguística esboçou uma teoria sobre o sujeito. Dadas as condições históricas, a formação intelectual e, não menos importante, os objetivos científicos do teórico, a manifestação concreta da categoria do sujeito não pôde ser efetivada. Em meados do século XIX, o cenário científico assistiu ao grande desenvolvimento das ciências naturais, cujos métodos influenciaram radicalmente as correntes filosóficas, sociológicas, antropológicas e, com o mesmo vigor e congruente intensidade, os conhecimentos linguísticos. A atmosfera desse período exigia das pesquisas e de seus realizadores o empreendimento de um objeto analítico indiferente a mudanças abruptas, apreensível em sua deriva e regularidade interna e, anatomicamente, sistemático. Podemos dizer que o momento reclamava dos linguistas uma matéria de estudo definível por si mesma, sob a pena de corromper o status de cientificidade tão necessário à aceitabilidade e validação das descobertas. Torna-se coerente, assim, a inserção da língua, vista em sua organicidade estrutural, na categoria de objeto científico.

Certamente, essa escolha mostrou-se tão cara à Linguística como também ao próprio Saussure. A partir daí, surgiram as severas, oportunas e, não em número menor, as inconsistentes críticas dirigidas aos seus postulados. Embora, na atualidade, tenhamos acesso a investigações que desenham um cientista com visões epistemológicas distintas daquele que encontramos, tortuosamente, desenhado no Cours de Linguistique Générale - CLG, grande parte das linhas da Linguística Contemporânea ainda sente êxtase em ignorar a essência de suas inquietações. Prefere fechar os olhos ou torcer o nariz ante a iminência de uma revisão nos conceitos e, principalmente, à vista de um movimento intenso de releituras. A publicação dos Escritos de Saussure lança uma luz precisa sobre muitas das indagações que tangenciam o Curso. Este, todavia, com todas as suas lacunas, ainda constitui uma obra magistral, seja por sua importância para a inauguração de uma ciência, seja por concentrar a essência do pensamento do ilustre professor de Genebra.

\section{A língua inventa o homem: rastros do sujeito}

Esse preâmbulo em torno das ideias de Saussure se revela necessário por julgarmos possível a constatação, no CLG, de vestígios que demarcam, veladamente, a atuação de um 


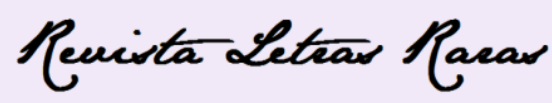

ISSN: 2317-2347 - Vol. 5, Ano 5, № 1 - 2016

sujeito. Com isso, podemos inferir, com a cautela necessária, que algumas observações esboçadas pelo linguista deixam entrever os germens de uma postura relativamente enunciativa, mesmo que esta não tenha sido conscientemente premeditada. Quando elege a língua o objeto da Linguística, Saussure não institui uma diáspora, banindo para o degredo perpétuo a fala. É extremamente pertinente sua posição acerca do caráter acidental, irregular e circunstancial dos atos vocais. A impossibilidade de visualizá-los como um todo coerente o faz inclinar-se, favoravelmente, pela língua. Ao contrário daqueles, esta se configura como um sistema, ou seja, um conjunto de unidades solidárias que se organizam mediante princípios internos, consubstanciando um artefato estruturalmente apreensível. Tais caracteres convergem para o ideal de objeto pretendido. Convém, aqui, sublinhar o caráter não taxativo, não excludente e não retalhador desse projeto. Existe, em total estado de latência, uma posição conciliadora nas aferições do mestre. A concordância advém quando declara que a interdependência entre língua e fala funda a linguagem, constitui o fator crucial e indispensável para o seu funcionamento. Na esteira do pensamento saussureano, "a linguagem tem um lado individual e um lado social, sendo impossível conceber um sem o outro" (SAUSSURE, 1989, p.16).

Como podemos averiguar, a individualidade é concebida como um traço caracterizador da fala. Tal propriedade nos faz recuperar a projeção de um agente que detém a faculdade de manifestá-la e, por conseguinte, modificá-la. É certo que Saussure circunscreve o acontecimento dentro dos limites da exteriorização fisiológica dos movimentos vocais, impedindo qualquer interpretação que venha associá-lo a outras causas ou origens. Contudo, não é a natureza do fato que nos chama a atenção. Sua arquitetura funcional revela-se mais prodigiosa. O exercício da fala, ainda que individual, é capaz de provocar alterações nas práticas linguísticas de seus usuários. Ao determos, nessa afirmativa, conseguimos figurar, mentalmente, a formação embrionária de um princípio enunciativo: o uso inflige transformações à língua. Logicamente, quando usamos o termo uso, estamos delimitando sua área de atuação e, por isso, excluímos as acepções de ordem pragmática e discursiva. No entanto, fazemos questão de mantermos o significado enunciativo.

Sabemos que Saussure, ao prescrever a "agressão" da fala sobre a língua, faz referência a mudanças estruturais, ou seja, aquelas situadas nos domínios da fonética, da organização sintática e da morfologia. Mesmo assim, não deixa de ser um pensamento "adjacente" à enunciação. Não podemos enxergar o processo enunciativo somente pela ótica 


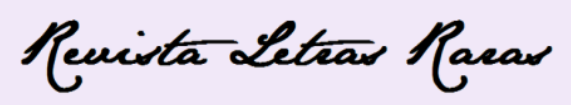

ISSN: 2317-2347 - Vol. 5, Ano 5, № 1 - 2016

da expressão ideológica, do mascaramento de intencionalidades ou da representatividade pragmática. Há uma faceta que obedece a princípios estritamente linguísticos (caso consideremos um evento comunicativo construído, também, por semioses verbais). É impossível pensar o processo dissociado dos mecanismos que o envolvem. A captação e transmissão de informações, dadas as suas condições e ferramentas de produção, requerem uma série de ajustes e contratos gramaticais, não necessariamente normativos, que garantam a sua efetivação e inteligibilidade (BARBOSA, 1996, p.35). Essa qualidade, no circuito das combinações vocais, apresenta-se mais perceptível, dadas as peculiaridades do evento. Talvez a volatilidade da fala, responsável por operar variações no sistema (as quais exigiriam, na época em questão, um exame de casualidades a ele externas), tenha impulsionado o Pai da Linguística a afastá-la de suas inquirições científicas. As respostas que ele buscava reivindicavam que tal atitude fosse tomada. Aqui, encontram-se, as palavras do notório linguista que, destarte, se expressa:

São as impressões recebidas ao ouvir os outros que modificam nossos hábitos linguísticos. Existe, pois, interdependência da língua e da fala; aquela é ao mesmo tempo o instrumento e o produto desta. [...] A fala é a soma do que as pessoas dizem, e compreende. (SAUSSURE, 1989, p. 27)

Afastamento parece ser a palavra de ordem quando nos referimos às polêmicas saussureanas. O conceito de exclusão subleva-se dissonante em meio a uma teorização que objetivava a delimitação de uma categoria abstrata complexa, concomitantemente encapsulada por conteúdos heteromórficos. Torná-los, de tal modo, periféricos revelou-se uma saída de mestre. Não obstante, a problemática é tão tentacular que ultrapassou as fronteiras nucleares e chegou, com força, às esferas funcionais. Comecemos, conquanto imbuídos de um certo temor, por averiguar o duelo entre sincronia e diacronia. Mais uma vez, ressaltemos o viés de nossas deduções. Saussure, por sua ordem histórica, priorizou em suas observações os deslocamentos sígnicos no interior do sistema, sem desprezar, obviamente, a influência das coerções temporais sobre a fisiologia das estruturas. Era evidente que as línguas se deixavam corromper pela atuação humana, reiterada incessantemente no decorrer da vida (FIORIN, 2002, p.56). Essa consciência foi a desencadeadora de uma ação que consentiu à língua um cárcere espontâneo, fronteiriço e, o mais excepcional, sem algozes, ou seja, ela passou a ser enquadrada num "tabuleiro" onde seus movimentos eram garantidos, observados mas não externamente determinados. 


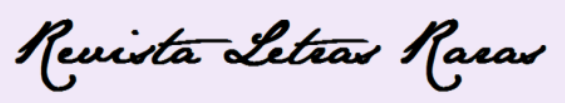

ISSN: 2317-2347 - Vol. 5, Ano 5, № 1 - 2016

É louvável e grandioso o teor das conclusões do ousado linguista. As tortuosas interpretações que sobrevieram à difusão de suas ideias são resultantes, em sua maioria, de condutas discordantes que visavam, a todo custo, rechaçar a importância do empreendimento, como também de posicionamentos convergentes que se contentaram em admitir, sem uma prévia reflexão, dados isolados de um fecundo e instável aporte teórico. Em hipótese alguma, negaremos a prioridade atribuída aos movimentos sincrônicos. Faremos apenas a seguinte reserva: tomar a língua como um sistema de unidades síncronas não significa dizer que estas estejam orbitando, permanentemente, em torno do eixo do estatismo e da imutabilidade. É bem verdade que, na concepção saussureana, as incisões cronológicas, operadas na língua, permitiriam lobrigar os fatos linguísticos, independentemente de sua evolução no tempo (CÂMARA JR, 1975, p. 76). Estranhamente, encontramos no CLG, passagens que ratificam a incoerência e nulidade dessa premissa, tal qual: "uma língua é radicalmente incapaz de se defender dos fatores que deslocam, de minuto a minuto, a relação entre o significado e o significante. É uma consequência da arbitrariedade do signo" (SAUSSURE, 1989, p. 90).

A usual e, não menos sublime, metáfora do tabuleiro de xadrez, descaracterizada e avivada pela crítica, matiza bem o comportamento sincrônico do sistema. A instituição do jogo corresponderia a um dado recorte ou estágio de uma língua qualquer. A base do artefato, espacialmente quadricular, simboliza as dimensões estruturais do sistema. Nela, as peças encontram-se dispostas em lugares significativos, de onde emanam os valores que serão, estrategicamente, assimilados. Se estamos nos referindo a um jogo, com leis que devem ser obedecidas, então chegamos à conclusão que deslocamentos, hesitações e perdas de posições são naturalmente iminentes. Saussure, contudo, debruçou-se, com maior circunspecção, sobre o movimento das peças, inspecionando-lhes o valor adquirido ao angariarem novas posições na intrincada dinâmica do conscrito tabuleiro. As feições assumidas durante a partida fazem dessas estruturas figuras únicas, de tal modo que, negativamente, aproximam-se, afastam-se e se distinguem. A identidade linguística está, nessa relação diferencial, intrinsecamente estabelecida (CÂMARA JR, 1975, p. 73).

Abandonar o terreno dos jogadores, concentrando-se metodologicamente na comedida agitação semântica que se opera entre os elementos internos de um sistema denominado língua, consagrou-se uma habilidosa jogada ou, não menos provável, uma ardilosa retirada estratégica. O fundador da Linguística Moderna, ao desenhar as configurações de um recôndito dispositivo comunicativo, estruturalmente situado em dois 


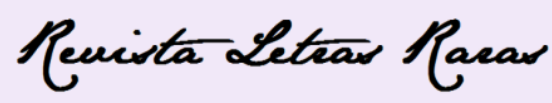

ISSN: 2317-2347 - Vol. 5, Ano 5, № 1 - 2016

eixos temporais divergentes e, simultaneamente, indissociáveis, determinou-se em favor da noção de variabilidade que, aos olhos científicos, servia perfeitamente aos seus propósitos teóricos. A conjectura de uma língua, moldada conforme o conceito de estrutura, exigia uma mobilidade parcial, ou melhor dizendo, passível de ser controlada, prevista e, sobretudo, aprisionada. Saussure não lança ao abismo a diacronia. Afugenta-a para um outro domínio onde entidades externas assenhoram as regras e os resultados são imprevisíveis. A coerência do linguista é, ao mesmo tempo, óbvia e labiríntica. Em seus postulados, o indivíduo é incapaz de adquirir a língua em sua totalidade. Ela constitui um bem social, armazenado e compartilhado solidariamente entre os partícipes de um grupo. Em contrapartida, esse mesmo ser reúne as qualidades necessárias para submeter tal tesouro a alterações, modificando-o gradativamente. Gerenciar o fenômeno diacrônico implicava, naquele momento, examinar a performance de um indivíduo dentro e fora do sistema. Isso contrariaria, sobremaneira, o ideal de ciência a ser alcançado.

Todavia, trazer à luz as particularidades dos esquemas sincrônicos e diacrônicos, da forma como tais mecanismos foram concebidos dentro de uma obra "controversa" tal qual o CLG, deixou rastros profundos, certamente não-premeditados, de uma tênue orientação enunciativa. O modelo sincrônico comporta movimentos da ordem do sentido. $\mathrm{O}$ valor logrado pelos signos (ou peças), dentro dos limites do sistema (ou tabuleiro), provém dos deslocamentos semânticos decorrentes das relações de diferença e semelhança que aí se manifestam, residem e permanecem. Razoavelmente, o processo enunciativo, assim como o definimos, variavelmente, na contemporaneidade, entrever, em proporções muito maiores, as movências do sentido (FIORIN, 2002, p. 83). Os estudos saussureanos compreendem, apenas, uma parcela ínfima desse nebuloso processo, considerando-o em frágeis e inacabados traços formais. Ainda assim, podemos depreender uma linha semântica, anuviada de ditos, interditos e não-ditos, que corrobora a existência de um sistema estrutural obediente, momentaneamente, às leis do movimento. Essa inconstância permite-nos visualizar, embora sensivelmente, os resquícios de uma marcação enunciativa, não propriamente dita, mas epistemologicamente descontínua (BARTHES, 1984, p. 105).

Para irrompermos uma enunciação, devemos, antes, instituirmo-nos como adversários em um dado jogo ou combate. Este, enquanto categoria a priorística, só existe como virtualidade e, nessa condição, suas regras são puramente ideais e não reais. $O$ tabuleiro, da maneira como é esquematizado, parece ter funcionamento autônomo. As peças 


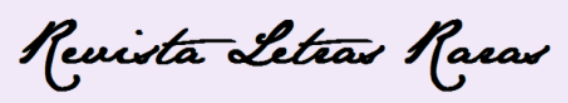

ISSN: 2317-2347 - Vol. 5, Ano 5, № 1 - 2016

se movimentam sem intervenção alguma, desencadeiam relações e, o mais surpreendente, o percurso demarcado não se mostra significativo. A alegoria, bastante contestável, serviu para dá forma e ilustrar uma Linguística que "tem por único e verdadeiro objeto a língua considerada em si mesma e por si mesma" (SAUSSURE, 1989, p. 271). Essa afirmação, utilizada pelos editores do CLG, como axioma conclusivo das ideias do Saussure, impregnouse de tal forma, nos curso de Letras, que anulou a própria figura do autor (se é que ele realmente a proferiu). O irrefutável é que o conceito se transformou numa verdadeira mácula vitalícia. Ironicamente, poucos são aqueles que leram integralmente a obra, mas, na certa, muitos são os que retiveram apenas essa proposição e, o pior, reiteram-na como se fosse algo inquestionável (BARBOSA, 1996, p. 63). Até que ponto, essa língua, de princípios unilaterais, que se volta sobre si mesma, desconsiderando o ente que dela faz uso, é criação única do linguista de Genebra? As contradições encontradas no livro podem servir a uma provável elucidação da questão.

Como já fizemos questão de registrar, não se pode conjecturar, nos escritos do eminente linguista, um estudo condensado sobre o índice sujeito. As tentativas de apagá-lo foram copiosamente diligentes. Tanto esforço, contudo, sucumbiu à própria teorização que exigia a referência, mesmo que sub-reptícia, ao íncola vitalício do mundo enunciativo. $\mathrm{O}$ malogro tornou visíveis as tênues "pegadas" de um ser que se constrói a partir de marcas legadas por ditos aparentemente inacabados ou sequencialmente discrepantes. A incursão silenciosa do sujeito, nos alfarrábios saussureanos, torna-se mais saliente quando tentamos compreender o fenômeno da arbitrariedade do signo, como também, no momento que nos dirigimos rumo à percepção operacional das intrigantes associações sintagmáticas e paradigmáticas. Ao descrever o princípio da arbitrariedade sígnica, Saussure defende o caráter imotivado do significante em relação ao significado. Para ele, não há uma ligação lógica e natural que corrobore a união entre o conceito e a imagem acústica. Em outros termos, não cabe ao indivíduo atribuir ao significante o significado que lhe pareça conveniente, visto que as estruturas da língua são edificadas coletivamente (PAIS, 1979, p. 43). Embora o laço, entre elas, seja, incontestavelmente, arbitrário, os valores adquiridos pelos signos dependem do fato social, aqui, considerado enquanto pluralidade de indivíduos que compartilham algo em comum, ou seja, a língua. Detenhamo-nos, nesse momento, na seguinte passagem do CLG:

Por sua vez a arbitrariedade do signo nos faz compreender melhor que o fato social pode, por si só, criar um sistema linguístico. A coletividade é 


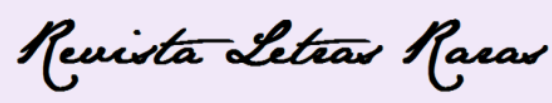

ISSN: 2317-2347 - Vol. 5, Ano 5, № 1 - 2016

necessária para estabelecer os valores cuja única razão de ser está no consenso geral; o indivíduo, por si só, é incapaz de fixar um que seja. (SAUSSURE, 1989, p. 132)

Sem a máxima da arbitrariedade, o fenômeno linguístico se reduzia a um mero instrumento de associação de nomes, isto é, uma nomenclatura. Sob esse ponto de vista, os signos se ordenariam de forma matematicamente biunívoca (para cada conceito corresponderia uma estrutura acústica particular) e a língua, nesse âmbito, não cumpriria sequer sua função primeira: comunicar (BARTHES, 1984, p. 57). Assim, prescrever um elo convencional entre o significado e o significante é pôr em evidência o princípio constitutivo de todo e qualquer sistema linguístico. Nenhuma língua, sejam quais forem seus elementos semiológicos, permanece alheia a tal mecanismo, posto que o nascimento de novas unidades e a extinção de outras são fatores cruciais para a sobrevivência de um dado aparato linguageiro. É a partir do conceito de arbitrariedade que as relações polissêmicas se manifestam, configuram-se e se consolidam. E, trazer à tona o complexo processo de polissemia, é pôr em discussão a intervenção de agentes externos capazes de construir, modificar e extinguir significados e estruturas fonológicas. Desse modo, a possibilidade de uma única imagem acústica receber diversos revestimentos conceituais sanciona a atuação de indivíduos que, ao se comunicarem, promovem, em comunhão, mudanças na língua (FIORIN, 2002, p. 48).

A polissemia é a prova cabal da presença de energias enunciativas, decorrentes especificamente da atividade de entes externos, orbitando em tono de um sistema, aparentemente fechado, denominado língua. Se os traços semânticos de um dado componente sígnico são determinados a partir do confronto com outros elementos de mesma natureza, ou seja, "o valor de um resulta tão-somente da presença simultânea de outros" (SAUSSURE, 1989, p. 133), então chegamos à inferência de que o engendramento do sentido, ainda que em nível puramente estrutural, acontece sempre em decorrência de um certo teor de reciprocidade entre os sujeitos. As unidades da língua só se constituem - o significado vincula-se a um significante - em razão do intercâmbio comunicativo entre os usuários. Estes partilham de um aparato referencial, congruente ao universo biossocial que os circunda, capaz de legitimar a combinação arbitrária entre as duas faces do signo. Em nenhuma circunstância, o fenômeno linguístico, tomado em si mesmo, poderia se encarregar de estabelecer ligações que extrapolam o estrato intra signo. 


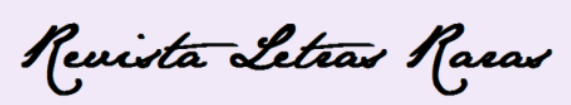

ISSN: 2317-2347 - Vol. 5, Ano 5, № 1 - 2016

Saussure, entretanto, tenta negligenciar a importância do sujeito, impondo à própria língua o papel de agente articulador. Cabe a ela, na visão do renomado linguista, servir de instrumento mediador entre o pensamento caótico e a matéria fônica (PAIS, 1979, p. 35), promovendo condições necessárias para que as ideias se constituam e se manifestem harmoniosamente. Para demonstrar a atuação da língua frente à organização do pensamento, o genebrino lança mão de outra analogia - a das massas amorfas. Em seu didatismo, ele apresenta o pensamento e a expressão fônica como planos paralelamente sobrepostos, formados, cada um, por massas amorfas distintas. A língua, nessa exemplificação, obtém suas unidades e, por conseguinte, se constitui ao perpassar os dois planos, subdividindo-os e, ao mesmo tempo, articulando-os. Cada recorte produz o acoplamento do pensamento com a estrutura fônica. Dessa associação, resulta o signo, considerado enquanto forma e não substância (SAUSSURE, 1989, p. 131). O termo substância faz referência aos mínimos caracteres conceptuais e fonológicos que compõem um dado elemento sígnico. Nesse sentido, Saussure enfatiza a ideia de completude das unidades linguísticas, escamoteando o conceito de signo como entidade inacabada. Eis a seguinte diagramação:

IMAGEM 1: Massas amorfas

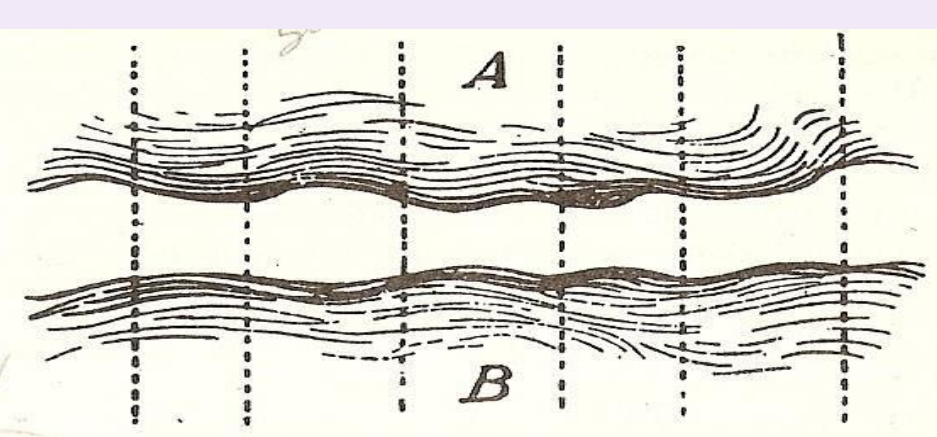

FONTE: (SAUSSURE, 1989, p.131)

Como percebemos, ao direcionar nossos olhos para a figura, a língua se define pelas inúmeras e infinitas articulações que opera sobre os planos A (pensamento desorganizado) e B (matéria fônica). Entretanto, é bastante óbvio que, metonimicamente falando, a língua ocupa uma posição que pertence, de fato, ao sujeito. Somente ele, enquanto detentor do sistema, teria condições de promover o agrupamento entre os dois seguimentos amorfos, 


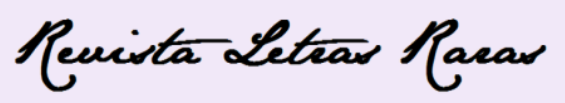

ISSN: 2317-2347 - Vol. 5, Ano 5, № 1 - 2016

tornando-os passíveis de veicular conteúdos significativos. Essa dedução torna-se verdade na medida em que os signos só significam porque os indivíduos, que deles fazem uso, atribuemlhes sentido. Não estamos fazendo menção a sujeitos ideológicos, mas a sujeitos antropologicamente definidos, que possuem a faculdade da linguagem e, consequentemente, fazem uso solidário de um sistema linguístico tangenciado por experiências culturais. Muitos estudiosos assinalam o caráter antropológico como limitação dos estudos saussureanos, o que nos parece, pois, um dizer dispensável. O imprescindível é não esquecer que a noção de sistema carece desse revestimento. Não estamos diante de um fenômeno isolado que se autorregula e se autoconserva, mediante intervenção única e exclusiva de "energias" internas. Ele existe em função de um grupo, de uma comunidade que o alimenta e o torna funcional. E, certamente, o processo enunciativo engloba desde a aquisição da língua(gem) à sua utilização coletiva ou individual.

Se averiguarmos, com um pouco mais de atenção, a definição de língua como forma e não substância, teremos a oportunidade de trazer à tona algumas ideias bastante relevantes para nosso estudo. Para tanto, abriremos um pequeno interstício para situarmos o grande linguista dinamarquês, Louis Hjelmslev, considerado pela crítica como um dos mais perspicazes leitores de Saussure. Hjelmslev desenvolve uma sólida teorização sobre o plano de conteúdo e o plano de expressão, onde os conceitos de forma e substância ganham contornos bem mais precisos. Em seus Prolegômenos (1975), concebe o signo como uma grandeza diretamente ligada à relação de reciprocidade entre os dois planos, a qual produz uma acumulação de cargas significativas, denominada de função semiótica. Esta compreende um imbricado maquinário de produção de sentido cujos movimentos obedecem a preceitos enunciativos de base organicamente estrutural. Para que a significação se manifeste é necessário que as unidades da língua estejam numa subordinação algébrica de tal sorte que as sentenças se solidarizem, produzindo o texto (processo). Sob esse ângulo, os sentidos estariam intimamente relacionados aos índices referenciais agregados à língua por intermédio dos vínculos comunicativos instituídos pelos indivíduos. Assim, "parece justo que um signo seja signo de alguma coisa e que essa alguma coisa resida de algum modo fora do próprio signo" (HJELMSLEV, 1975, p. 61). A referência é, nesse caso, um apanágio da tênue linha enunciativa, de arrimos explicitamente formais.

A associação mútua entre os estratos da expressão e do conteúdo, assim como as condições discursivas a eles relacionadas, caracteriza, em matizes bem intensas, a natureza 


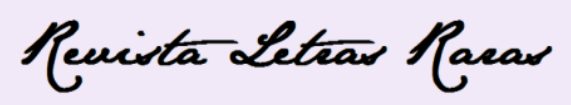

ISSN: 2317-2347 - Vol. 5, Ano 5, № 1 - 2016

heteromórfica de uma função semiótica de veio estrutural. Isso nos leva a refletir acerca de alguns modelos formais de descrição e análise linguísticas que, por vezes, desprezam as posturas enunciativas por conceberem um conceito extremamente rígido de estrutura. A severidade nos princípios revela, muitas vezes, um desconhecimento da natureza das línguas. Estudá-las em sua imanência não implica ignorar os fatores a elas exteriores, como se fossem objetos proscritos, estanques e estáticos. Deparamo-nos, inclusive, com abordagens radicais que enclausuram o sistema em seus próprios preceitos, extinguindo, por completo, toda preocupação transcendente. $\mathrm{O}$ estruturalismo hjelmsleviano, com suas orientações matemáticas, tentou conciliar, até certo ponto, o imanente e a exterioridade, a regularidade e o imprevisível. Essas relações se processam tanto no seio do texto e como no seio do sistema, sendo consequência, obviamente, da dialética existente entre a expressão e o conteúdo. Este corresponde ao mundo de pensamentos que, considerados dentro de uma macro esfera de comunicação, podem servir a níveis distintos de concretização semiológica. A expressão constitui o aspecto externo da língua, isto é, a cobertura sonora, gráfica ou qualquer outro envoltório do pensamento nela materializado. Cada nível conserva uma forma e uma substância específicas. E o indivíduo é aquele que tem por função estabelecer os laços entre os dois níveis e as unidades que os compõem (CÂMARA JR, 1975, p. 17).

Nos escritos do linguista suíço, a substância, apesar de servir como matéria para formação das unidades sígnicas, não define a língua. Esse papel compete unicamente à forma. Dessa maneira, o teórico descura, metodologicamente, etapas que deixam entrever o mecanismo de produção dos signos em suas mínimas unidades. É sabido que sua ação consiste em fragmentar o signo numa dualidade macro estrutural. $O$ dinamarquês, ao contrário, faz o movimento inverso, partindo do exame das micro unidades que dão corpo à substância e à forma dos planos da expressão e conteúdo para, em seguida, preceituar a fusão entre os dois funtivos. A forma de conteúdo engloba as relações entre as unidades sêmicas, ou seja, refere-se à própria estruturação das ideias. Já a substância de conteúdo é o pensamento ainda não estruturado (amorfo), ou seja, a projeção mental da realidade extralinguística.

Os índices fonológicos ou os grafemas ainda não sistematizados na língua constituem a substância da expressão. Esses elementos são providos de um determinado valor linguístico, visto que traduzem, em dados significativos, a matéria sonora resultante dos movimentos orgânicos das cordas vocais, como também da atividade fisiológica das cavidades bucal e nasal. No que tange à forma de expressão, a mesma abarca as relações estruturais entre os 


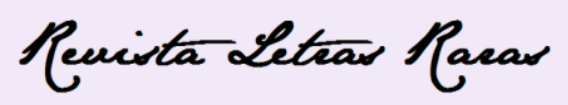

ISSN: 2317-2347 - Vol. 5, Ano 5, № 1 - 2016

sons. Representa, em outras palavras, o valor funcional dos fememas na cadeia da fala/discurso. Isso significa dizer que a função distintiva não se restringe ao simples confronto entre os fonemas, mas ocorre, na mesma proporção, entre grandezas maiores, isto é, atinge desde as palavras até o texto.

À vista disso, a enunciação cumpre a função de promover a diferença e a identidade, em nível estrutural, das unidades constituintes da língua. A cada novo ato comunicativo, os signos se atualizam, adquirindo feições semânticas próprias. Esse fenômeno recebe o nome de semiose e caracteriza-se pelo ato produtor de significação, gerado numa correlação entre signo-usuário-discurso. Depreende-se, pois, que a concepção de processo, utilizada por Hjelmslev para se referir inicialmente aos atos de fala (texto), passa a abarcar também o sistema, cujo dinamismo semiótico organiza, continuamente, os códigos e subcódigos que o constituem. Nesse sentido, pode-se inferir que o sistema produz o discurso que, por vez, transforma o sistema, num movimento ininterrupto de autoalimentação e autorregulagem da função semiótica. A esse respeito afirma Barbosa (1996):

Temos, pois, na função semiótica e na semiose que a instaura, os elementos fundamentais para a proposição de um modelo mais dinâmico de sistema de signos, já que, inclusive, uma propriedade essencial do signo é a de poder comporta-se tanto como signo-objeto - quando substitui, por assim dizer, o 'objeto' do qual esse signo é signo -, quanto poder comportar-se como metasigno - quando substitui não já um 'objeto', diretamente, mas, sim, outros signos (BARBOSA, 1996, p. 38).

Cerrando o lapso das considerações hjelmslevianas, regressemos às projeções sintagmáticas e paradigmáticas idealizadas por Saussure, com o escopo de validar a hipótese de que um pensamento enunciativo, por mais que este seja adjacente, se faz presente em seus escritos. Na visão do linguista, a língua se presta à comunicação graças às erupções do paradigma na frágil cadeia sintagmática. A mente organiza os signos em compartimentos segundo as feições semânticas e mórficas que apresentam. O contato com o outro impõe-nos a necessidade de expressão de nossos desejos, ideias e temores. Nesse momento, somos levados a romper o lacre dos compartimentos e extrair os signos que consideramos apropriados para a manifestação daquilo que sentimos. Não restam dúvidas de que estamos diante de uma diagramação enunciativa. As escolhas e sua projeção somente ocorrem em função de um confronto entre sujeitos. As passagens seguintes, extraídas do CLG, podem demonstrar a validade de nossas reflexões: 


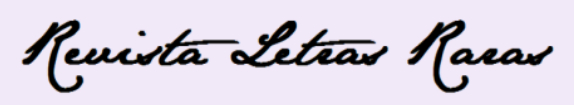

ISSN: 2317-2347 - Vol. 5, Ano 5, № 1 - 2016

Os grupos formados por associação mental não se limitam a aproximar os termos que apresentem algo em comum; o espírito capta também a natureza das relações que os unem em cada caso e cria com isso tantas séries associativas quantas relações diversas existam (SAUSSURE, 1989, p.145).

[...] pois o espírito descarta naturalmente as associações capazes de perturbarem a inteligência do discurso (SAUSSURE,1989, p.145).

Aliás, sãos estes seres que procedem às seleções e, conscientemente ou não, fazem emergir as estruturas sintagmáticas a partir das quais os ditos se constituem. Saussure comete um ato falho ao responsabilizar o espírito como a entidade capaz de gerenciar todo o processo. O deslize instaura, à revelia do autor, um sujeito que se apodera do sistema e age sobre ele. Embora essa denominação possa dar impressão de que estamos diante de ente abstrato, situado à margem da língua, não é o que acontece. O espírito surge como categoria simétrica às relações que forjam o fenômeno linguístico.

\section{Considerações Finais}

O homem encontra-se tão envolvido com o mundo de possibilidades ofertado pela linguagem que chega ao ponto de confundir-se com ela própria. É impossível, segundo Saussure, pensar o indivíduo isolado das eventualidades comunicativas que o constitui. Sob esse foco, torna-se indispensável uma reflexão prudente sobre a funcionalidade da língua e da linguagem. A primeira, "fabricada" em seus códigos e subcódigos, assegura a expressão particular daqueles que dela comungam. Suas unidades se deixam macular pelas investidas dos sujeitos que, compartindo de uma mesma comunidade, cruzam-se, anunciam-se e se descobrem. Assim, a subjetividade surge como fenômeno inscrito na língua por intermédio da enunciação. A segunda é responsável por promover o discurso enquanto acontecimento. Compreende a força ativa, armazenada nas entranhas do homem, impelindo-o ao confronto com os outros, o que contribui, consideravelmente, para a singularidade do evento que o envolve.

A língua é um dos instrumentos de que serve o sujeito para fazer significar a realidade ao seu redor. É adquirida, como bem assinalou Saussure, no bojo de um grupo, cujos integrantes se juntam para viver de acordo com as normas de um determinado instituto, seja político, religioso ou, no caso em questão, linguístico. Esse contrato coletivo, a qual 


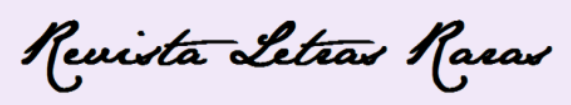

ISSN: 2317-2347 - Vol. 5, Ano 5, № 1 - 2016

todos devem se submeter, é apenas uma parte, embora de grande relevância, de um imenso contraforte semiótico conhecido como linguagem. Em relação a esta, o homem não é nem senhor nem vassalo. Entre ambos, sem que se possa contestar, temos uma condição de existência recíproca, ou seja, o estado de subsistência de um depende proporcionalmente da permanência, continuidade e estabilidade (ou instabilidade) do outro. A linguagem está para a espécie humana assim como o enunciado está para a enunciação.

\section{Referências}

BARBOSA, Maria Aparecida. Léxico, produção e criatividade. São Paulo: Plêiade, 1996.

BARTHES, Roland. O rumor da língua. São Paulo: Edições 70, 1984.

CAMARA JR., Joaquim Mattoso. História da linguística. Rio de Janeiro: Vozes, 1975.

CHARAUDEAU, Patrick; MAINGUENEAU, Dominique. Dicionário de Análise do Discurso. São Paulo: Contexto, 2004.

DUBOIS, Jean et alli. Dicionário de linguística. São Paulo: Cultrix, 1993.

FIORIN, José Luiz. As astúcias da enunciação: as categorias de pessoa, espaço e tempo. São Paulo: Ática, 2002.

HJELMSLEV, L. Prolegômenos a uma teoria da linguagem. São Paulo: Perspectiva, 1973.

PAIS, Cidmar Teodoro. Manual de linguística. Rio de Janeiro: Vozes, 1979.

ROBINS, R. H. Pequena história da linguística. Rio de Janeiro: Ao Livro Técnico, 1983.

SAUSSURE, Ferdinand de. Curso de linguística geral. São Paulo: Cultrix, 1989.

Recebido em: 25/03/2016

Aceito em: 30/06/2016 